\title{
DIAGNÓSTICO E TRATAMENTO EMPÍRICO DE INFECÇÕES BACTERIANAS AGUDAS
}

\author{
DIAGNOSIS AND EMPIRICAL TREATMENT OF ACUTE BACTERIAL INFECTIONS
}

Roberto Martinez \& José Fernando de Castro Figueiredo

${ }^{1}$ Docentes. Divisão de Moléstias Infecciosas e Tropicais. Departamento de Clínica Médica. Faculdade de Medicina de Ribeirão Preto - USP. CorRespondÊncia: Roberto Martinez. Departamento de Clínica Médica. Faculdade de Medicina de Ribeirão Preto - USP.

Av. Bandeirantes, 3.900; - CEP 14048-900 Ribeirão Preto - SP, Brasil. rmartine@fmrp.usp.br; FAX: (16) 633-6695.

MARTINEZ R \& FIGUEIREDO JFC. Diagnóstico e tratamento empírico de infecções bacterianas agudas. Medicina, Ribeirão Preto, 36: 345-350, abr./dez. 2003

RESUMO: Este roteiro de condutas proporciona informações sobre o diagnóstico e terapia antimicrobiana, empírica, para casos agudos de pneumonia, meningite e septicemia.

UNITERMOS: Pneumonia. Meningite. Septicemia. Terapia Antimicrobiana.

\section{1- INTRODUÇÃO}

A abordagem clínica do paciente com infecção aguda deve ser minuciosa e ampla, visando possibilitar o início de um tratamento empírico, que tenha grande chance de ser eficaz. Febre, sudorese, adinamia, inapetência e mesmo algumas outras manifestações, como cefaléia, vômitos, mialgia e artralgia, são sintomas gerais e caracterizam as síndromes inflamatória e infecciosa. Uma etapa fundamental do processo diagnóstico é a identificação do foco ou dos focos de infecção, o que irá direcionar a terapia específica. Neste sentido, devem ser priorizados os sinais e sintomas cujos significados convergem para o comprometimento do mesmo órgão ou sistema.

O hemograma é muito solicitado na investigação das infecções agudas, mas, comumente, revela apenas leucocitose, neutrofilia, linfocitopenia e eosinopenia discretas, sugestivas de resposta adaptativa ao estresse. Leucocitose superior a $15.000 / \mathrm{mm}^{3}$, acompanhada das mesmas alterações e de granulações tóxicas ou microvacúolos em neutrófilos, é sugestiva de infecção por bactérias Gram-positivas ou Gram- negativas. Leucopenia, neutropenia, linfocitose relativa e presença das mesmas alterações qualitativas sugerem infecção intestinal ou urinária por bacilos Gramnegativos, febre tifóide e, excepcionalmente, infecções graves por pneumococo. O diagnóstico de viroses e da toxoplasmose adquirida, aguda pode ser presumido, quando houver quadro hematológico de neutropenia e linfocitose, absolutas ou relativas, principalmente se associadas à presença de linfócitos atípicos. Infecções mais graves ou persistindo além de poucos dias são investigadas com exames em busca do foco infeccioso e com cultura de sangue e de outros fluidos. Em razão de apresentarem quadro clínico pobre ou atípico, pacientes geriátricos e imunossuprimidos podem requerer investigações laboratorial e de imagem mais extensas, como radiografia torácica, mesmo na ausência de sintomas respiratórios.

\section{2- PNEUMONIA}

Pneumonias bacterianas, de origem comunitária, em adultos, têm, como causa principal, o pneumococo, seguindo-se outros: estreptococos, estafilococos, 
bacilos Gram-negativos e bactérias anaeróbicas. Embora o pneumococo continue predominando, os pacientes com mais de 60 anos de idade, os etilistas e os imunossuprimidos apresentam, com maior freqüência, infecções por bacilos Gram-negativos. As pneumonias aspirativas em doentes da comunidade relacionam-se com estreptococos e anaeróbicos da orofaringe. As pneumonias atípicas, que podem causar taquipnéia e dispnéia importantes, conforme o grau de inflamação do interstício pulmonar, resultam de infecção por vírus, micoplasma, legionela, clamídia, riquétsia ou fungos. Pneumonias hospitalares podem ser causadas pelos mesmos agentes citados anteriormente, contudo estafilococos e bacilos Gram-negativos têm papel etiológico mais importante, em frequiência e na resistência a antimicrobianos.

A radiografia de tórax é exame indispensável à comprovação do diagnóstico de pneumonia. Agentes bacterianos provocam exsudação em alvéolos e aspecto radiológico de infiltrado flocoso, desde um pequeno foco até áreas extensas e bilaterais de velamento, sendo o aspecto de velamento lobar ou segmentar resultante, comumente, de infecção pneumocócica. As pneumonias atípicas relacionam-se com infiltrado intersticial, observado como trama reticulada e micronódulos, associando-se, em parte dos casos, a velamento flocoso. Outros exames laboratoriais são indicados em casos mais graves de pneumonia, incluindo hemograma, gasometria, função renal, eletrólitos e testes microbiológicos e sorológicos. Os resultados dos exames feitos de urgência, mais a avaliação clínica, são usados para estimar a gravidade do caso, parâmetro a ser considerado na conduta terapêutica. $\mathrm{O}$ risco de morte, em pacientes com pneumonia, é proporcional à idade, leucocitose, alterações bioquímicas e extensão das alterações radiológicas, aumentando, quando se associam alcoolismo, câncer, doenças crônicas, imunossupressão e bacteremia ${ }^{(1)}$. Os pacientes com maior gravidade devem ser hospitalizados e tratados com esquemas antimicrobianos mais abrangentes. O tratamento de pacientes com pneumonia, em geral, é iniciado empiricamente, com base nos prováveis agentes causadores ${ }^{(2,3)}$. Para tanto, são consideradas as evidências clínicas, radiológicas e laboratoriais disponíveis, juntamente com dados microbiológicos prévios sobre infecções comunitárias, locais. A Tabela I apresenta sugestões de esquemas terapêuticos para casos de baixa a alta gravidade, conforme os tipos de pneumonia. Cerca de $20 \%$ dos pneumococos isolados, no Brasil, apresentam re- sistência intermediária à penicilina, mas não há necessidade de modificar a terapia convencional. Pneumococos com alta resistência são infrequientes, sendo combatidos com vancomicina ou com quinolonas, como levofloxacina, gatifloxacina e moxifloxacina. Pacientes ambulatoriais, com diversos tipos de imunossupressão (diabéticos, etilistas, leucêmicos, etc.), são mais amplamente colonizados por diversos agentes de pneumonia e podem requerer terapia antimicrobiana diferente da sugerida na Tabela I, especialmente se já tiverem sido hospitalizados.

\section{3- MENINGITE}

O diagnóstico clínico das meningites baseia-se no reconhecimento das síndromes infecciosa, hipertensiva e radicular. A coleta e exame do líquido cefalorraquiano (LCR) são fundamentais para estabelecer o diagnóstico etiológico e o tratamento de doentes com meningite. Número de células superior a $500 / \mathrm{mm}^{3}$, predomínio de neutrófilos, proteína elevada e glicose reduzida no LCR sugerem meningite purulenta. A bactéria causadora pode ser identificada por meio de coloração Gram do sedimento do LCR, cultura do LCR, pesquisa de antígenos (teste do látex) no LCR, ou por hemocultura. Número de células inferior a 500, predomínio de linfomononucleares, proteína e glicose normais ou discretamente alteradas, são dados de LCR sugestivo de meningite virótica. Nesta condição, a presença de neutrófilos obriga a um diagnóstico diferencial com meningite purulenta, parcialmente tratada e com abscesso cerebral. Celularidade inferior a $500 / \mathrm{mm}^{3}$, predomínio de linfomononucleares, proteína total superior a $100 \mathrm{mg} / \mathrm{dL}$ e glicose abaixo de $40 \mathrm{mg} / \mathrm{dL}$, são alterações de LCR sugestivas de meningite granulomatosa (ocasionalmente, os pacientes podem apresentar celularidade mais elevada e predomínio de neutrófilos). O exame liquórico, em tal tipo de meningite, deve ser completado com culturas para fungos e micobactérias, pesquisa de antígeno criptocócico e sorologia para cisticercose, sífilis, toxoplasmose e infecções fúngicas.

A antibioticoterapia para meningites bacterianas purulentas, em adultos, está esquematizada na Tabela II, considerando situações nas quais o agente é conhecido ou casos em que a prescrição será empírica. São empregadas doses médias a altas de antibióticos, mantidas até o final do tratamento, e administradas via endovenosa, iniciando-se o mais rapidamente possível $^{(4,5)}$. A terapia empírica para meningites 
Tabela I: Tratamento antimicrobiano, empírico, de adultos com pneumonia

Gravidade

Tipo de pneumonia

1) Comunitária, pacientes com 14 a 60 anos de idade, velamento alveolar (agentes prováveis: pneumococo, estreptococos, hemófilos, moraxela)

2) Comunitária, paciente $>60$ anos de idade(ou com comorbidades), velamento alveolar (agentes prováveis: os mesmos do item 1, maior frequiência de bacilos Gram-negativos).

3) Comunitária, provavelmente estafilocócica

4) Comunitária, aspirativa (agentes prováveis: estreptococos e anaeróbicos).

5) Comunitária, atípica, velamento intersticial (com ou sem velamento alveolar) (agentes prováveis: micoplasma, clamídia, legionela)

6) Hospitalar, bacteriana (agentes prováveis: os mesmos dos itens 1 a 4) maior freqüência de enterococos, estafilococos e bacilos Gram-negativos
Baixa a média

Amoxicilina VO, $500 \mathrm{mg}$ 8/8 h, 7 dias OU Eritromicina VO, $500 \mathrm{mg}$ $6 / 6 \mathrm{~h}$, 7 dias (*)

Amoxicilina - ácido clavulânico VO, $500 \mathrm{mg} \mathrm{8/8} \mathrm{h} \mathrm{OU} \mathrm{Cefuroxima} \mathrm{VO,}$ $500 \mathrm{mg} \mathrm{12/12h}$

Média a Alta

Amoxicilina (com ou sem ácido clavulânico) EV, 1 g 8/8 h OU

Ceftriaxona EV, $1 \mathrm{~g}$ 12/12 h (ou

Cefuroxima EV, $750 \mathrm{mg}$ 8/8h).(**)

Amoxacilina -ácido clavulânico EV, 1 g 8/8 h OU Ceftriaxona EV, $1 \mathrm{~g} \mathrm{12/12}$ h (**)

Oxacilina EV, 2 g 6/6 h +

Gentamicina EV,

$1 \mathrm{mg} / \mathrm{Kg}$ de peso $8 / 8 \mathrm{~h}$.

Clindamicina VO, $300 \mathrm{mg}$ 8/8 h OU Amoxicilina - ácido Clavulânico VO, $500 \mathrm{mg} 8 / 8 \mathrm{~h}$

Clindamicina EV, 450-600 mg 8/8 h OU Amoxicilina - ácido clavulânico EV, 500 mg - 1g 8/8 h.

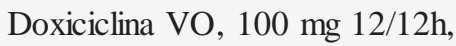
14-21 dias OU Eritromicina VO, 500 mg 6/6 h 14-21 dias (*)

Ceftriaxona EV, 1-2 g 12/12h OU Ceftriaxona $\mathrm{EV}+$ Amicacina $\mathrm{EV}$, $500 \mathrm{mg}$ 12/12 h OU Ciprofloxacina EV, 200-400 mg 12/12 h.
Claritromicina EV, 15mg/Kg 12/12 h

OU Azitromicina EV OU fluoroquinolona $\mathrm{EV}$

Esquema individualizando o estado do paciente, fatores causais, antibioticoterapia prévia e local de hospitalização (resistência bacteriana)

(*) Outras opções: Novos macrolídeos e fluoroquinolonas com ação antipneumocócica;

(**) Em casos com insuficiência respiratória, associar macrolídeo ou fluoroquinolona EV.

Obs: As doses indicadas são para adultos com função renal e hepática normais.

comunitárias é dirigida contra pneumococo, meningococo e estreptococo, os principais agentes em adultos e, geralmente, sensíveis à ampicilina e à penicilina $\mathrm{G}$. Havendo evidências da participação de pneumococo com resistência intermediária ou alta à penicilina $\mathrm{G}$, hemófilos, estafilococo ou bacilos Gram-negativos, ou quando o paciente estiver mais comprometido, ou, ainda, quando se tratar de idoso, etilista ou imunossuprimido, inicia-se ceftriaxona. Meningite estafilocócica, comunitária associa-se com trauma craniano ou com infecção disseminada. Pode ser controlada com ceftriaxona, mas deve, preferencialmente, ser tratada com oxacilina ou vancomicina. A meningite purulenta, adquirida em hospital, tem, como agentes principais, estafilococo, enterobactérias e Pseudomonas aeruginosa, sugerindo-se iniciar tratamento empírico com vancomicina mais ceftazidima. Além da antibioticoterapia, corticosteróides - como dexametasona, 4 mg 6/6hs EV - são utilizados durante alguns dias, em pacientes com vasculite por doença meningocócica e em doentes com sinais de hipertensão intracraniana, grave. Também, podem ser necessários antitérmicos, antieméticos, anticonvulsivantes e hidratação parenteral com soro glicosado a $5 \%$. Contudo, o volume 
Tabela II: Tratamento antimicrobiano das meningites bacterianas purulentas em adultos

Etiologia

$1^{\mathrm{a}}$ opção

Pneumococo sensível à penicilina $\mathrm{G}$, meningococo, estreptococos, listeria

Pneumococo com resistência alta ou intermediária à penicilina $\mathrm{G}$

Hemófilos

Staphylococcus aureus

Escherichia coli

Klebsiella pneumoniae

Outras enterobactérias

Pseudomonas aeruginosa

Meningite comunitária, etiologia desconhecida ou duvidosa, em adulto < 60 anos, sem alterações de consciência ou sinais neurológicos focais

Meningite comunitária, etiologia desconhecida. Adultos $\geq 60$ anos, etilistas, imunossuprimidos, ou pacientes com alteração de consciência / sinais neurológicos focais

Meningite hospitalar, etiologia desconhecida

Antimicrobianos

$2^{\mathrm{a}}$ opção

Ampicilina, 2g 4/4 h, OU Penicilina G cristalina, 4 a 5 milhões unid. $4 / 4 \mathrm{~h}$

Ceftriaxona, $2 \mathrm{~g} \mathrm{12/12h}$

Ceftriaxona, 2g 12/12 h

Oxacilina, $3 \mathrm{~g}$ 6/6h +

Gentamicina, 1 a $1,5 \mathrm{mg} / \mathrm{Kg}$ de peso, $8 / 8 \mathrm{~h}$

Ceftriaxona, $2 \mathrm{~g} \mathrm{12/12h} \mathrm{OU}$

Ceftazidima, $2 \mathrm{~g} 8 / 8 \mathrm{~h}$

Ceftazidima, $2 \mathrm{~g} 8 / 8 \mathrm{~h}+$

Amicacina, $500 \mathrm{mg} \mathrm{12/12} \mathrm{h}$

Ampicilina, 2g 4/4h

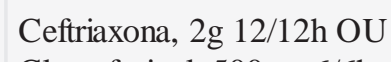

Cloranfenicol, 500mg 6/6h

Vancomicina, 500mg 6/6h

Ceftriaxona, $2 \mathrm{~g} \mathrm{12/12 \textrm {h } +}$

Cloranfenicol, 500mg 6/6h

Vancomicina, 500mg 6/6 h

Imipenem, 500mg 6/6h (OU

Meropenem, 2 g EV 8/8h)

Imipenem, 500mg 6/6h OU

Aztreonam, 2g 8/8h (OU

Meropenem)

Ceftriaxona, $2 \mathrm{~g} \mathrm{12/12h} \mathrm{OU}$

Cloranfenicol, 500mg 6/6h
Ceftriaxona, $2 \mathrm{~g} \mathrm{12/12h}$

Vancomicina, 500mg 6/6h + Ceftazidima, $2 \mathrm{~g} 8 / 8 \mathrm{~h}$
Ceftriaxona, $2 \mathrm{~g} \mathrm{12/12 \textrm {h } +}$ Ampicilina, 2g 4/4h OU Ceftazidima, $2 \mathrm{~g} 8 / 8 \mathrm{~h}+$ Ampicilina, $2 \mathrm{~g} 4 / 4 \mathrm{~h}$

Vancomicina, 500mg 6/6h + Imipenem, 500mg 6/6h (OU Vancomicina + Meropenem)

Obs.: 1) todos os antibióticos são administrados por via EV, sendo que penicilina $\mathrm{G}$, vancomicina e amicacina requerem infusão lenta; 2) a duração do tratamento, no mínimo de 10 a 15 dias, é determinada pela melhora clínica e neurológica; 3) priorizar o antibiograma, quando estiver disponível; 4) as doses indicadas são para adultos com função renal e hepática normais; 5) Imipenem pode causar crise convulsiva em pacientes com inflamação do SNC.

diário total de líquidos não deve ultrapassar $2.500 \mathrm{~mL}$, para não agravar a hipertensão intracraniana.

As meningites viróticas são causadas, principalmente, por enterovírus e não há necessidade de tratamento específico, apenas medicação para controle dos sintomas. Entretanto, casos com quadro de encefalite predominante têm maior probabilidade de etiologia por vírus herpes simples, havendo indicação de aciclovir (10 mg/Kg de peso, 8/8 h, 10 - 14 dias). Os pacientes com meningite granulomatosa são trata- dos de acordo com a causa da infecção, após confirmação laboratorial, quando o estado clínico permite.

\section{4- SEPTICEMIA}

O diagnóstico de septicemia é estabelecido, quando o paciente apresenta dois ou mais focos de infecção, acompanhados de bacteremia (ou fungemia) e de comprometimento das funções orgânicas. É essencial conhecer o agente causal, o que pode ser obti- 
do com culturas de sangue, 2 amostras iniciais (veias diferentes), e logo antes do tratamento, e de outros fluidos relacionados com os focos infecciosos. Também é importante solicitar hematológico, RX de tórax, gasometria, eletrólitos e exames de avaliação da função renal e hepática. A septicemia em adultos não hospitalizados é causada, mais freqüentemente, por pneumococo, estreptococo, estafilococo, Escherichia coli e outras enterobactérias. Em pacientes hospitalizados, são prevalentes estafilococos coagulase-negativos, S. aureus, bacilos Gram-negativos (incluindo P. aeruginosa) e espécies de Candida.

A terapia antimicrobiana deve ser iniciada de imediato, em doses elevadas e por via endovenosa ${ }^{(6)}$, se possível, dirigida para agentes causadores do foco infeccioso primário ${ }^{(7)}$. As infecções comunitárias do pulmão e da pele e subcutâneo são, geralmente, causadas por bactérias Gram-positivas, podendo ser controladas com cefalosporinas de primeira à terceira geração, oxacilina, amoxicilina - ácido clavulânico ou vancomicina. Infecções urinárias usualmente, têm, como agentes etiológicos, bacilos Gram-negativos, sendo possível a prescrição amoxicilina - ácido clavulânico, aminoglicosídeos, cefalosporinas de segunda a terceira geração e quinolonas. Quando a infecção generalizada tem início em vias biliares ou no intestino, suspeita-se de enterobactérias e de anaeróbicos, que são combatidos com associações de antimicrobianos, combinando-se aminoglicosídeo, ceftriaxona ou ciprofloxacina com metronidazol ou clindamicina. Os pacientes com septicemia relacionada com infecção comunitária e cuja etiologia é desconhecida são medicados empiricamente, com esquemas que atuam simultaneamente sobre bactérias aeróbicas Gram-positivas e Gram-negativas. Mais utilizadas são as associações de cefalosporinas com aminoglicosídeos, em geral, cefalotina, cefuroxima ou ceftriaxona com gentamicina ou amicacina; ampicilina ou oxacilina são preferidas às cefalosporinas na suspeita de, respectivamente, enterococo e estafilococo. A septicemia de origem abdominal ou pélvica pode ter a coparticipação de anaeróbicos, sugerindo-se iniciar a terapia com clindamicina mais amicacina ou acrescentar metronidazol, como terceiro antiinfeccioso, aos esquemas acima mencionados. Quando a septicemia é decorrente de infecção hospitalar, é necessário considerar o nível de resistência bacteriana local, sabendo-se que é mais intensa e problemática em hospitais que prestam assistência a casos de nível terciário. Em tal situação, o tratamento empírico da septicemia pode requerer o uso de cefepime, vancomicina, quinolonas, carbapenêmicos, antifúngicos e outras drogas pouco usadas em infecções comunitárias.

Além dos antimicrobianos, o doente séptico requer monitorização cuidadosa e medidas terapêuticas complementares, quando desenvolve complicações, como choque circulatório e síndrome de angústia respiratória, do adulto. Então, pode ser útil o emprego de corticosteróide, como hidrocortisona $500 \mathrm{mg}$ $\mathrm{EV}, 6 / 6 \mathrm{~h}$, para reduzir o processo inflamatório prejudicial, resultante da liberação excessiva de citocinas e de outros mediadores. Outras medidas para choque cardiovascular são encontradas em outro artigo deste fascículo.

MARTINEZ R \& FIGUEIREDO JFC. Diagnosis and empirical treatment of acute bacterial infections. Medicina, Ribeirão Preto, 36: 345-350, apr./dec. 2003.

ABSTRACT: This guideline provides informations about the diagnosis and empirical antimicrobial therapy for acute cases of pneumonia, meningitis, and sepsis.

UNITERMS: Pneumonia. Meningitis. Septicemia. Antimicrobial Therapy.

\section{REFERÊNCIAS BIBLIOGRÁFICAS}

1 - BARTLETT JG; BREIMAN RF; MANDELL LA \& FILE Jr TM . Community - acquired pneumonia in adults: guidelines for management. Clin Infect Dis 26: 811-838, 1998.
2 - CAZZOLA M; BLASI F \& ALLEGRA L. Critical evalution of guidelines for the treatment of lower respiratory tract bacterial Infections. Respir Med 95: 95-108, 2001.

3 - HUCHON G; WOODHEAD M; GIALDRONI - GRASSI G; LÉOPHONTE P; MANRESA F; SCHABERG T; TORRES A; 
DIDIER A; DORCA J; EL EBIARY M \& ROCHE N. Guidelines for management of adult community - acquired lower respiratory tract infections. Eur Respir J 11: 986-991, 1998.

4 - TUNKEL AR \& SCHELD WM. Acute bacterial meningitis. Lancet 346: 1675-1680, 1995

5 - QUAGLIRELLO VJ \& SCHELD WM. Treatment of bacterial meningitis. N Engl J Med 336: 708-716, 1997.
6 - HOSPITAL DAS CLÍNICAS DA FACULDADE DE MEDICINA DE RIBEIRÃO PRETO USP. COMISSÃO DE USO E CONTROLE DE ANTIMICROBIANOS (CUCA). Manual de antimicrobianos. HCFMRP-USP, Ribeirão Preto, 2001/2002.

7 - WHEELER AP \& BERNARD GR. Treating patients with severe sepsis. N Engl J Med 340: 207-214, 1999. 